\title{
ESTAQUIA COMO PROCESSO DE CLONAGEM DO BACURIPARI (Redhia gardneriana Miers ex Planch e Triana $)^{1}$
}

\author{
DANILO FRANCO ${ }^{1}$, INEZ VILAR DE MORAIS OLIVEIRA ${ }^{2}$, ÍTALOHERBERT LUCENACAVALCANTE ${ }^{2}$, PAULOEDUARDO \\ CERRI $^{3}$, ANTONIO BALDO GERALDO MARTINS ${ }^{4}$
}

RESUMO - No Brasil, existem diversas fruteiras nativas com potencial de exploração comercial, especialmente na Amazônia, local de origem do bacuripari. Neste sentido, realizou-se um trabalho com o objetivo de avaliar a clonagem dessa espécie pelo processo da estaquia, mediante uso de ácido indolil-3-butírico (AIB), em condições de nebulização intermitente. O delineamento experimental foi o inteiramente casualizado, com 5 tratamentos, caracterizados pelas concentrações de AIB $\left(0 ; 1.000 ; 3.000 ; 5.000\right.$ e 7.000 mg.L L $\left.^{-1}\right)$, com 4 repetições e 10 estacas por parcela. Foram avaliados na porcentagem de estacas enraizadas, o número médio de folhas e o comprimento de raízes. O uso de AIB não influenciou na porcentagem de enraizamento.

Termos para indexação: propagação vegetativa, regulador de crescimento, frutas exóticas.

\section{CUTTING AS CLONING PROCESS OF BACURIPARI (Redhia gardneriana Miers ex Planch e Triana)}

ABSTRACT - In Brazil there are several native fruitful with commercial potential, specially in Amazon which is the origin of bacuripari species. Thus it was carried out a research work aiming to evaluate the viability of cutting process on bacuripari cloning, using indole3-butyric acid (IBA) under conditions of intermittent mist, on FCAV/UNESP, Jaboticabal County, Brazil. The experimental design was completely randomized with 5 treatments, characterized by IBA concentrations $(0 ; 1,000 ; 3,000 ; 5,000$ and 7,000 mg.L-1 $)$, with 4 repetitions and 10 cuttings per parcel. It was evaluated the percentage of cuttings rooted, the average number of leaves and the length of roots. The use of IBA had no influence on percentage of cuttings rooted.

Index terms: vegetative propagation, growth regulator, exotic fruit.

O bacuripari é uma frutífera pertencente à família Clusiaceae. O fruto é carnoso e contém até quatro sementes envolvidas por uma polpa branca, mucilaginosa e, às vezes, bastante ácida. Embora esteja disperso até o Paraguai, tem provável origem amazônica, onde é encontrado em matas de terra firme e em várzeas, igapós e capoeiras, sendo cultivado em toda a região. O período de floração ocorre entre junho e novembro, e o amadurecimento dos frutos, de agosto a fevereiro do ano subseqüente (Donadio et al., 1998).

A propagação por estaquia é um dos métodos mais importantes de clonagem utilizados na horticultura porque proporciona a fixação de genótipos selecionados, uniformidade de populações, facilidade de propagação, antecipação do período de florescimento, redução do estádio juvenil e maior controle das fases de desenvolvimento (Hartmann et al., 2002). Diversos fatores influenciam nesse método de propagação, como genótipo, condições fisiológicas da planta-matriz, tipo de estaca e condições ambientais (Menzel, 1985 e Calabrese, 1978).

O objetivo do fornecimento exógeno de substâncias reguladoras de crescimento é proporcionar maior porcentagem de enraizamento, uniformidade do material, produtividade em menor espaço de tempo e menor permanência da estaca no leito de enraizamento (Zuffellato-Ribas \& Rodrigues, 2001).
Dentre as substâncias reguladoras de crescimento, as auxinas são as mais utilizadas no enraizamento em estacas, por apresentarem relação direta com a formação de raízes laterais e adventícias (Taiz e Zeiger, 2004). Dentre as auxinas, destaca-se o ácido indolbutírico (AIB), pela sua maior resistência à degradação por ação da luz, inativação por ação biológica e maior aderência à estaca (Hoffmann et al., 1996 e Hartmann et al., 2002). Ono et al. (1992) utilizaram vários tratamentos para a formação de raízes em estacas de canela (Camellia japonica L.) e observaram que aqueles que continham AIB foram mais eficientes na promoção do enraizamento.

O objetivo deste trabalho foi estudar a viabilidade de propagação do bacuripari pelo processo de estaquia com o uso de auxina, sob condições de nebulização intermitente.

O trabalho foi desenvolvido na Área Experimental de Produção de Mudas Frutíferas do Departamento de Produção Vegetal da Faculdade de Ciências Agrárias e Veterinárias UNESP, Câmpus de Jaboticabal-SP.

Estacas apicais herbáceas foram coletadas de plantasmatrizes, na região mediana da copa, em pleno desenvolvimento vegetativo, no mês de agosto, e padronizadas com $15 \mathrm{~cm}$ de comprimento, 1 par de folhas inteiras e 3 pares de gemas.

As estacas foram submetidas à aplicação do AIB

\footnotetext{
(Trabalho 111-2005). Recebido em 26-07-2005. Aceito em 04-12-2006.

${ }^{2}$ Pós-Graduandos em Agronomia - FCAV/UNESP, Depto de Produção Vegetal. Via de acesso Prof. Paulo Donato Castellane, s/n. Cep: 14884-900. Jaboticabal/SP. Tel/Fax: (16)3209-2668. franco.danilo@gmail.com; inezvilar@yahoo.com; italohlc@fcav.unesp.br

${ }^{3}$ Engenheiro Agrônomo. pauloedcerri@yahoo.com.br.

${ }^{4}$ Prof. Doutor - FCAV/UNESP - Depto de Produção Vegetal. baldo@fcav.unesp.br
} 
(MerckÒ, Alemanha), metodologia descrita por Hartmann et al. (2002), através da imersão da base por 10 segundos e, posteriormente, transportadas para caixas plásticas de 30 x 50 x $10 \mathrm{~cm}$ contendo vermiculita de grânulos médios, em casa de vegetação com $50 \%$ de luminosidade e mantidas sob nebulização intermitente. O tempo de nebulização adotado foi de 15 segundos espaçados de 45 segundos, controlados por um temporizador.

O delineamento experimental utilizado foi o inteiramente casualizado, com 5 tratamentos, caracterizados pelas concentrações de AIB $(0 ; 1.000 ; 3.000 ; 5.000$ e 7.000 mg.L-1 $)$, com quatro repetições e cada parcela composta por 10 estacas.

Após 60 dias da instalação do experimento, avaliaram-se o número das folhas por estacas, o comprimento das raízes e a porcentagem de estacas enraizadas.

Os resultados foram submetidos à análise de variância para avaliação de efeito estatístico, e foi realizada análise de correlação linear simples entre as variáveis número de folhas e comprimento de raízes e regressão simples, utilizando-se do software Statistica (STATSOFT, 2001).

A aplicação de AIB (Tabela 1) não apresentou efeito significativo para porcentagem de estacas enraizadas, concordando com Bastos et al. (2004), quando da avaliação do AIB na formação de raízes em estacas herbáceas e lenhosas de caramboleira, como Leonel \& Rodrigues (1993) e Biasi et al. (1997), em videira, que também não observaram aumento significativo no enraizamento de estacas, sob condições controladas com a aplicação de AIB. Em outras culturas, observou-se que o AIB também não influenciou na taxa de sobrevivência, como Martins (1998), em lichieira e Roncatto et al. (1999) e Roberto et al. (2001), em laranjeira 'Valência'.

O baixo percentual de estacas enraizadas, em todas as concentrações da auxina adotadas no estudo, pode ser atribuído ao estádio vegetativo da planta, uma vez que, de acordo com Hartmann et al. (2002), estacas de ramos juvenis têm maior capacidade de enraizamento; ou, ainda, pode ter tido influência da época de coleta do material, que, de acordo com Fachinello et al. (1995), influencia no sucesso do resultado. Por outro lado, apesar do baixo percentual de estacas enraizadas, verificaram-se diferenças numéricas evidentes entre os níveis de AIB testados, registrando-se melhor ajuste dessa variável ao modelo quadrático, com aumento progressivo até o nível de $5.000 \mathrm{mg} . \mathrm{L}^{-}$ ${ }^{1}$ seguido de um decréscimo (Figura 2). Jarvis et al. (1983) explicam que há um nível ótimo de auxina para o enraizamento de estacas, a partir do qual o processo é prejudicado.

TABELA 1 - Porcentagem de enraizamento, número médio de raízes e comprimento de estacas de bacuripari (Redhia gardneriana Miers ex Planch e Triana), tratadas com diferentes concentrações de AIB, FCAV/UNESP, Jaboticabal-SP, 2005.

\begin{tabular}{clcc}
\hline & \multicolumn{3}{c}{ Quadrados médios } \\
\cline { 2 - 4 } & $\begin{array}{c}\text { Número médio } \\
\text { de folhas }\end{array}$ & $\begin{array}{c}\text { Porcentagem de estacas } \\
\text { enraizadas }\end{array}$ & $\begin{array}{c}\text { Comprimento médio } \\
\text { de raízes }(\mathrm{cm})\end{array}$ \\
\hline Níveis de AIB & $0,01789^{* *}$ & $140,86700^{\text {ns }}$ & $0,03162^{* *}$ \\
Resíduo & 0,00248 & 50,13072 & 0,00734 \\
\hline CV & 56,11 & 63,93 & 60,28 \\
\hline ** &
\end{tabular}

** - significativo para $\mathrm{p} \leq 0,01 ;{ }^{\mathrm{ns}}=$ não-significativo.

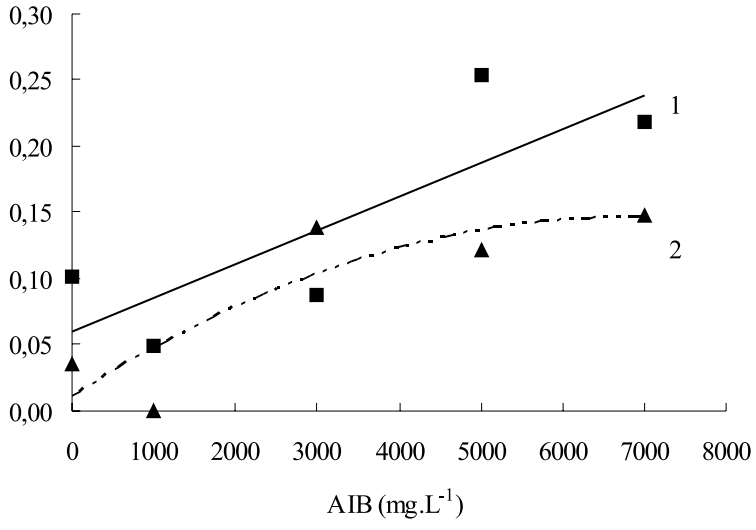

1 - Comprimento de Raízes $-R^{2}=0,671 ; y=3 E-05 x+0,0608$

2 - Número de Folhas $-\mathrm{R}^{2}=0,759 ; \mathrm{y}=-3 \mathrm{E}-09 \mathrm{x}^{2}+4 \mathrm{E}-05 \mathrm{x}+0,0106$

FIGURA 1 - Comprimento de raízes (linear) e número médio de folhas (quadrática) em estacas de bacuripari, em função de níveis de AIB.

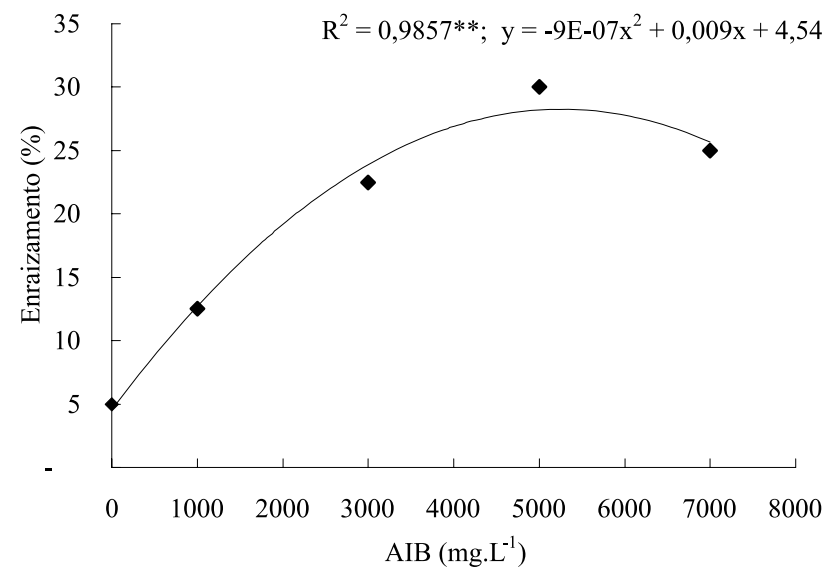

FIGURA 2 - Percentagem de estacas enraizadas de bacuripari em função de níveis de AIB.

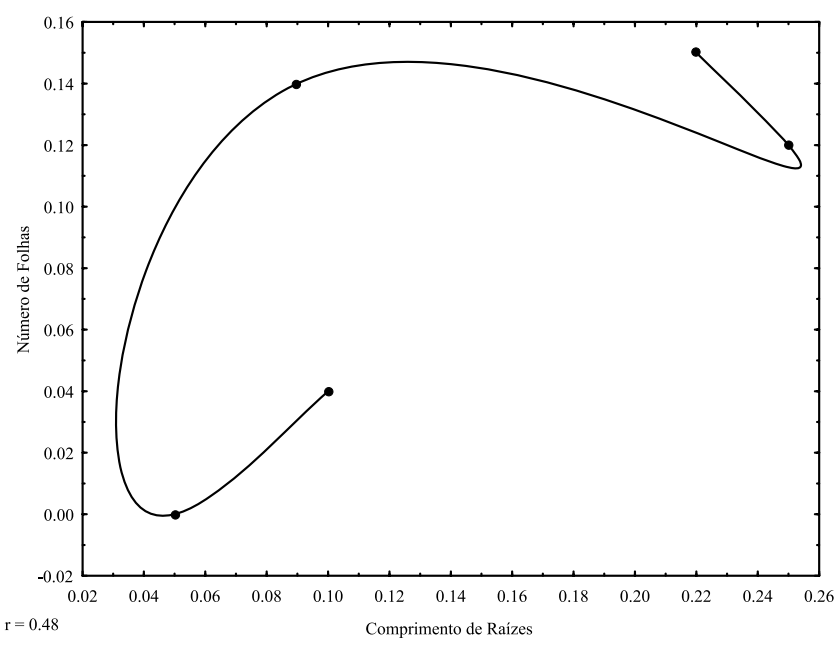

FIGURA 3 - Gráfico de correlação positiva para os parâmetros comprimento de raízes e número de folhas. 
Uma vez que o número médio de folhas e o comprimento médio de raízes, por estacas de bacuripari, foram significativamente influenciados a $1 \%$ de probabilidade, realizouse análise de regressão simples para as soluções concentradas de AIB em relação aos parâmetros comprimento médio de raízes e número médio de folhas, registrando-se melhor ajuste ao modelo linear para o comprimento médio de raízes e quadrático para o número médio de folhas (Figura 1) e baixos coeficientes de determinação $\left(\mathrm{R}^{2}\right)$, o que pode ser atribuído ao comportamento decrescente do comprimento médio de raízes do nível de 5.000 para $7.000 \mathrm{mg} . \mathrm{L}^{-1}$, como também observado do nível de 3.000 para $5.000 \mathrm{mg} . \mathrm{L}^{-1}$ para número médio de folhas.

Na Figura 1, observa-se que o comprimento médio de raízes foi maior, em torno de $0,26 \mathrm{~cm}$, na concentração de 5.000 mg. $\mathrm{L}^{-1}$ de AIB, decrescendo para o nível 7.000, possivelmente devido à inibição no alongamento da raiz primária causada após a concentração ótima de auxina, embora tenha acelerado a rizogênese, conforme reportado por Taiz \& Zeiger (2004). Para a variável número de folhas, o melhor resultado foi observado na concentração de $7.000 \mathrm{mg} \cdot \mathrm{L}^{-1}$.

As variáveis comprimento médio de raízes e número médio de folhas em estacas de bacuripari apresentaram correlação significativa a $5 \%$ de probabilidade, linear, positiva, com coeficiente de correlação $r=0,48$, portanto considerada média por Ferreira (2000) (Figura 3). Esse resultado indica semelhança de comportamento dessas variáveis em resposta aos níveis de AIB. Observa-se o primeiro ponto com valores de $(0,04$ e 0,1$)$ para valores de número de folhas e comprimento de raízes, e o último, com valores de $(0,15$ e 0,22$)$, respectivamente.

Sob as condições em que o trabalho foi realizado, permitese concluir que:

Não há influência da concentração de auxina (AIB) na porcentagem de estacas enraizadas.

\section{REFERÊNCIAS}

BASTOS, D.C.; MARTINS, A.B.G.; SCALOPPI JÚNIOR, E.J.; SARZI, I.; FATINANSI, J.C. Influência do ácido indolbutírico no enraizamento de estacas de caramboleira (Averrhoa carambola L.) sob nebulização intermitente). Revista Brasileira de Fruticultura, Jaboticabal, v.26, n.2, p. 284286, 2004.

BIASI, L.A.; POMMER, C.V.; PINO, P.A.G.S. Propagação de portaenxertos de videira mediante estaquia semilenhosa. Bragantia, Campinas, v.56, n.2, p. 367-376, 1997.

CALABRESE, F. Frutticoltura tropicale e subtropicale. Bologna: Coop. Lib. Un. Editrice, 1978. 498p.

DONADIO, L.C.; NACHTIGAL, J.C.; SACRAMENTO, C.K. Frutas exóticas. Jaboticabal: Funep, 1998. p.214-15.

FACHINELLO, J.C.; HOFFMANN, A.; NACHTIGAL, J.C.; KERSTEN, E.; FORTES, G.R. de L. Propagação de plantas frutíferas de clima temperado. 2.ed. Pelotas: UFPEL, 1995.178p.

FACHINELLO, J.C.; NACHTIGAL, JC.; KERSTEN, E. Fruticultura: fundamentos de práticas. Pelotas: UFPEL, 1996. 311. (não consta no texto)
FERREIRA P.V. Estatística experimental aplicada à agronomia. Maceió: Universidade Federal de Alagoas, 2000. 682p.

HARTMANN, H.T.; KESTER, D.E.; DAVIES JR, F.T.; GENEVE, R.L. Plant propagation: principles and practices. $7^{\text {th }} \mathrm{ed}$. New Jersey: Prentice-Hall, 2002. 880p.

HOFFMANN, A.; CHALFUN, N.N.J.; ANTUNES, L.E.C.; RAMOS, J.D.; PASQUAL, M.; REZENDE E SILVA; C. R. de. Fruticultura comercial: propagação de plantas frutíferas. Lavras: UFLA/FAEPE, 1996.319p.

JARVIS, B.C.; ALI, A.H.N.; SHAHEED, A.I. Auxin and boron in relation to the rooting response and ageing of mung bean cuttings. New Phytologist, Cambridge, v.95, p.509-518, 1983.

LEONEL, S.; RODRIGUES, J.D. Efeito da época de estaquia, fitorreguladores e ácido bórico no enraizamento de estacas de porta-enxertos de videira. Scientia Agricola, Piracicaba, v.50, n.1, p.27-32, 1993.

MARTINS, A. B. G. Enraizamento de estacas enfolhadas de três variedades de lichia (Litchi chinensis Sonn.). 1998. 100f. Tese (Doutorado em Agronomia) - Faculdade de Ciências Agrárias e Veterinárias, Universidade Estadual Paulista, Jaboticabal, 1998.

MENZEL, C.M. Propagation of lychee: a review. Scientia Horticulturae, Amsterdam, v. 25, n.1, p. 31-48, 1985.

ONO, E.O.; RODRIGUES, J.D.; PINHO, S. Z. do. Interações entre auxinas e ácido bórico, no enraizamento de estacas caulinares de Coffea arabica L. cv. Mundo Novo. Scientia Agricola, Piracicaba, v. 49, n.1, p. 23-27, 1992.

ROBERTO, S.R.; PEREIRA, F.M.; CAETANO, A.C. Efeito do ácido indolbutírico no enraizamento de estacas herbáceas de laranjeira 'Valência' (Citrus sinensis L. Osbeck). Revista Brasileira de Fruticultura, Jaboticabal, v.23, n.1, p. 206208, 2001.

RONCATTO, G.; GONÇALVES, E.D.; DUTRA, L.F.; KERSTEN, E. Influência do sombreamento das plantas e do ácido indolbutírico no enraizamento de estacas de laranjeira (Citrus sinensis L. Osbeck) Cv. Valência. Revista Científica Rural, Bagé, v.4, n.2, p.60-65, 1999.

STATSOFT. STATISTICA (data analysis software system), version 6. 2001.

TAIZ, L.; ZEIGER, E. Fisiologia vegetal. 3.ed. Porto Alegre: Artmed, 2004.719p.

ZUFFELLATO-RIBAS, K.C.; RODRIGUES, J.D. Estaquia: uma abordagem dos principais aspectos fisiológicos. Curitiba: Imprensa Universitária da UFPR, 2001.39p. 